\title{
Calcineurin Inhibitor Use and Myoclonus Association. Is There a Clinical Implication?
}

\author{
Ricardo E. Verdiner ${ }^{1}$, Ruben Casado Arroyo ${ }^{2}$, Mohammad Rauf Chaudhry ${ }^{3}$, Narjeet Khurmi ${ }^{1}$, \\ Karl Poterack ${ }^{1}$, Andy Gorlin 1 , Arun Jayaraman', Gustavo Rodriguez ${ }^{4}$ \\ ${ }^{1}$ Department of Anesthesiology, Mayo Clinic Arizona, Phoenix, USA \\ ${ }^{2}$ Department of Medicine, Universite Libre de Bruxelles, Brussels, Belgium \\ ${ }^{3}$ Department of Neurology, Texas Tech University, Lubbock, USA \\ ${ }^{4}$ Department of Neurology, Texas Tech University, Health Science Center of El Paso, Lubbock, USA \\ Email: *Verdiner.md@gmail.com
}

How to cite this paper: Verdiner, R.E., Arroyo, R.C., Chaudhry, M.R., Khurmi, N., Poterack, K., Gorlin, A., Jayaraman, A. and Rodriguez, R. (2021) Calcineurin Inhibitor Use and Myoclonus Association. Is There a Clinical Implication? Open Journal of Anesthesiology, 11, 85-98.

https://doi.org/10.4236/ojanes.2021.114009

Received: February 26, 2021

Accepted: April 3, 2021

Published: April 6, 2021

Copyright $\odot 2021$ by author(s) and Scientific Research Publishing Inc. This work is licensed under the Creative Commons Attribution International License (CC BY 4.0).

http://creativecommons.org/licenses/by/4.0/

\begin{abstract}
Background: Calcineurin Inhibitors (CNIs) play a pivotal role in anti rejection therapy for transplant patients. Neurotoxicity is a known side effect that usually manifests as encephalopathy but myoclonus has also been described. Perioperative myoclonus as a manifestation of neurotoxicity, has not been well studied. Methods: We retrospectively reviewed data from 842,762 patients from the Nationwide Inpatient Sample (NIS) database from January 2011 to December 2014. Of those records we compared 56,423 patients requiring CNIs and undergoing Heart Transplant (HT) with 786,339 patients undergoing Coronary Artery Bypass Graft (CABG) surgery as controls. The objective was to study the rates of myoclonus in patients undergoing cardiac surgery, especially those requiring CNIs, and study the outcome of those patients with myoclonus. The NIS database from January 2011 to December 2014 was the source for the analysis. Patients with underlying epilepsy or hypo-ischemic encephalopathy based on ICD-9-CM codes were excluded from the study. Results: A total of 147 patients $(0.26 \%)$ were found to have myoclonus in the HT group versus 338 patients $(0.04 \%)$ in the CABG group, $\mathrm{p}<$ 0.0001 . No differences in the demographics were seen except for kidney disease which was higher in the HT group. The difference remained statistically significant after adjusting for confounders. Patients with myoclonus in both groups were more likely to have acute kidney injury and have a prolonged length of stay. Only patients with myoclonus in the CABG group had higher rates of discharge disposition to a nursing home and higher rates of in-Hospital mortality. A trend towards higher in-Hospital mortality was found in patients with myoclonus in the HT group. Conclusion: In this study we have com-
\end{abstract}


pared the rate of myoclonus found in $\mathrm{HT}$ patients versus CABG patients. We have identified calcineurin inhibitors as potentially contributing to myoclonus due to its neurotoxic effects. The study also suggests that other disease processes like renal failure may also have an impact on the rate of myoclonus even in the absence of calcineurin inhibitors. Higher rates of myoclonus were seen in patients undergoing $\mathrm{HT}$ when compared to patients undergoing CABG, suggesting that CNIs may increase the risk for myoclonus. Myoclonus may be a clinical indicator of patient overall health including a more permeable blood brain barrier. In-Hospital mortality was higher in patients with myoclonus undergoing $\mathrm{CABG}$ and a trend towards significance in the HT group suggesting that it may be a marker of poor prognosis. More studies are needed to corroborate our findings.

\section{Keywords}

Calcineurin Inhibitors, Myoclonus, Neurotoxicity, Perioperative Mortality, Renal Failure, Tacrolimus, Mycophenolate, Endothelial Health, Blood Brain Barrier

\section{Introduction}

Movement disorders like tremors and less commonly myoclonus have been reported as adverse reactions of several classes of drugs. Myoclonus is clinically described as a sudden shock-like contraction of a muscle or group of muscles. Myoclonus can further be divided into physiologic and pathologic. Physiologic myoclonus is benign and often seen while falling asleep (hypnic myoclonus) or causing hiccupps (diaphragmatic myoclonus). Pathologic myoclonus can be categorized by three main causes: 1) hypoxia 2) drug toxicity and 3) metabolic disturbances [1].

Drug associated myoclonus usually resolves when the causative drug is removed [2]. For example, anesthetic agents have been described as a cause of myoclonus. In a 2017 study by Jansen et al., drugs associated with inducing/maintaining general anesthesia were the seventh most common drug class to cause myoclonus. Anesthetic agents, however, have a short term exposure to the patient as opposed to the anti-organ rejection drug class, which are a part of the long term management of transplanted patients. The CNI class includes cyclosporin and tacrolimus. Historically, they have been linked to neurotoxicity usually manifested as encephalopathy but myoclonus has also been reported [3]-[8]. Reactions like myoclonus are typically categorized as mild and acceptable given the life-extending outcome the drug is expected to provide [9]. Nevertheless, the association between antirejection drugs and perioperative myoclonus may have long term clinical implications. We sought to quantify the prevalence of myoclonus in heart transplant patients and its clinical relevance using a national dataset. 


\section{Methods}

\subsection{Data Source and Cleansing}

The United States Nationwide Inpatient Sample (NIS) is the largest all-payer inpatient care database designed to represent a $20 \%$ stratified sample of US hospitals or approximately $5-8$ million hospital stays using data from approximately 1000 hospitals. The NIS has been used in various studies to identify, track, and analyze national trends in healthcare utilization, access, charges, quality, and outcomes [10]. Given the size of the database, it was the preferred source for this study. More details on the design of the NIS are available at http://www.hcup-us.ahrq.gov.

The NIS database from 1 January 2011 to 31 December 2014 was used to analyze data from 842,762 patients. To avoid double representation, patients whose disposition or admission type indicated a transfer to or from another short-term hospital were excluded. Patients with a hospital charge of less than $\$ 100$ were likely coded incorrectly and were also excluded from the analysis. Similarly, patients with a negative LOS or LOS exceeding 365 days were eliminated from the dataset [11].

The International Classification of Disease, 9th Revision, Clinical Modification (ICD-9-CM) procedure code V42.1 was used to identify the 56,423 patients admitted for heart transplant. This approach has been used previously to estimate in-hospital mortality related to heart transplant in a large sample in the United States [12]. 786,339 patients admitted for CABG surgery were selected as the control group, using the ICD-9-CM procedure codes: $36.10,36.11,36.12$, $36.13,36.14,36.15$ and 36.16 [13]. Patients who developed myoclonus during the same hospitalization were determined using ICD-9-CM diagnosis code: 333.2. The presence of underlying epilepsy or hypo-ischemic encephalopathy was determined using ICD-9-CM diagnosis codes 345.0x-345.5x, 345.7x-345.9x, 780.39 and 768.70 , respectively and were removed from the study cohort.

\subsection{Variables}

The variables obtained for this study were: age, sex, and medical comorbidities i.e., hypertension (HTN), diabetes mellitus, coagulopathy, chronic lung disease, and renal failure [10] [14]. This information came from the Agency for Health Research and Quality comorbidity data files. Medical co-morbidities, i.e. dyslipidemia, and atrial fibrillation (Afib) were determined by using the ICD-9CM secondary diagnosis codes (272.40), and (427.31) respectively. ICD-9 secondary codes were used to identify in-hospital complications such as acute kidney injury $(584.9,39.95,54.98)$, pneumonia $(486,481,482.8$, and 482.3$)$, urinary tract infection (590.0, 590.9), and sepsis (995.91, 995.92, 996.64, 038, and 999.3). The length of stay, discharge disposition, and in-hospital mortality were determined using the variables "LOS", "DISPUNIFORM", and "died" from Agency for Health Research and Quality comorbidity data files. Prolonged length of stay (PLOS) was defined as length of stay more than 7 days. 


\subsection{Outcomes}

The outcomes of interest were prolonged length of stay greater than seven days, discharge disposition of alive patients to a nursing home and in-hospital mortality.

\subsection{Statistical Analysis}

The SAS 9.4 software (SAS Institute, Cary, NC) was used to convert NIS database data into weighted counts to generate national estimates, following Healthcare Cost and Utilization Project recommendations. Univariate analysis, Chisquare for categorical, and Analysis of variance (ANOVA) test for continuous variables were performed to identify differences in study variables and outcome endpoints. A statistically significant p-value was considered if $<0.05$.

This study was exempted from approval by the Texas Tech University Health Sciences Center El Paso Institutional Review Board as NIS is a public database with no personal identifying information.

\section{Results}

A total of 56,423 patients underwent HT during the study period of which 147 (0.26\%) patients had myoclonus while 786,339 patients underwent CABG of which $338(0.04 \%)$ had myoclonus $\{\mathrm{p}<0.0001\}$. Two medical comorbidities were different between the two groups in the univariate analysis. A total of 9 patients $(6.5 \%)$ in the HT + myoclonus group had atrial fibrillation and 131 patients $(38.8 \%)$ in the CABG + myoclonus group $\{\mathrm{p}<0.0001\} .94$ (64\%) patients in the HT + myoclonus group had renal failure and $96(28.4 \%)$ patients in the $\mathrm{CABG}+$ myoclonus group $\{\mathrm{p}=0.0002\}$. When comorbidities were adjusted for in the data set, the higher rates of myoclonus in the HT group remained statistically significant with a 5-fold difference observed, Table $1 \&$ Table 2 .

Patients with myoclonus in both groups had higher complications rates of acute kidney injury compared to patients without myoclonus in their respective groups, Table 3 \& Table 4. Similarly, patients with myoclonus in both groups had higher prolonged length of stay compared to patients without myoclonus. Patients in the CABG + myoclonus group had higher discharge disposition of alive patients to nursing home and higher In-Hospital mortality rates than patients without myoclonus, $\{p=0.002$ and $p=002\}$. This was not true for patients in the $\mathrm{HT}+$ myoclonus group, however there was a trend towards a statistically significant difference for higher in-Hospital mortality $\{p=0.08\}$, Table 5. All data regarding prolonged length of stay, discharge disposition of alive patient to a nursing home and in-hospital mortality were collected from the NIS database.

Table 1. Incidence of Myoclonus in HT and CABG.

\begin{tabular}{cccc}
\hline & Heart transplant & CABG & P value \\
& N: 56423 & N: 786339 & $338(0.04 \%)$ \\
With Myoclonus & $147(0.26 \%)$ & 0.0001 \\
Without Myoclonus & $56,276(99.74 \%)$ & $786,000(99.96 \%)$ & \\
With Myoclonus (renal failure excluded) & $(0.18 \%)$ & $(0.036 \%)$ & 0.012 \\
\hline
\end{tabular}


Table 2. Comparing basic CABG demographics.

\begin{tabular}{|c|c|c|c|}
\hline & $\begin{array}{l}\text { CABG with } \\
\text { myoclonus } \\
\mathrm{N}: 338\end{array}$ & $\begin{array}{l}\text { CABG without } \\
\text { myoclonus } \\
\mathrm{N}: 786,000\end{array}$ & $P$ value \\
\hline Age (mean \pm SD) & $65.2 \pm 14.4$ & $66.1 \pm 10.6$ & 0.50 \\
\hline Age $\geq 65$ yrs & $190(56.2 \%)$ & $453,855(57.7 \%)$ & 0.79 \\
\hline Female & $77(23.0 \%)$ & $210,623(26.8 \%)$ & 0.45 \\
\hline \multicolumn{4}{|l|}{ Medical Comorbidities } \\
\hline Diabetes Mellitus & $153(45.3 \%)$ & $338,597(43.1 \%)$ & 0.70 \\
\hline Congestive Heart Failure & 0 & $9619(1.22 \%)$ & - \\
\hline Hypertension & $264(78.0 \%)$ & $623,500(79.3 \%)$ & 0.79 \\
\hline Hyperlipidemia & $168(49.6 \%)$ & $497,390(63.3 \%)$ & 0.03 \\
\hline Atrial Fibrillation & $131(38.8 \%)$ & $262,069(33.3 \%)$ & 0.36 \\
\hline Renal Failure & $96(28.4 \%)$ & $125,667(15.9 \%)$ & 0.03 \\
\hline Hypercoagulable State & $103(30.6 \%)$ & $157,019(20.0 \%)$ & 0.05 \\
\hline Chronic Lung Disease & $84(0.24 \%)$ & $176,121(22.4 \%)$ & 0.64 \\
\hline \multicolumn{4}{|l|}{ In-hospital complications } \\
\hline Acute Kidney Injury & $132(39.1 \%)$ & $147,998(18.8 \%)$ & 0.001 \\
\hline Myocardial Infarction & $142(42.0 \%)$ & $237,641(30.2 \%)$ & 0.05 \\
\hline Pneumonia & $40(11.8 \%)$ & $37,105(4.72 \%)$ & 0.08 \\
\hline Urinary Tract Infection & $28(8.41 \%)$ & $53,923(6.86 \%)$ & 0.64 \\
\hline Sepsis & $18(5.55 \%)$ & $18,369(2.33 \%)$ & 0.24 \\
\hline \multicolumn{4}{|l|}{ Outcomes } \\
\hline Prolonged length of stay & $275(81.2 \%)$ & $515,605(65.6 \%)$ & 0.001 \\
\hline $\begin{array}{l}\text { Discharge disposition } \\
\text { of alive patients to } \\
\text { nursing home }\end{array}$ & $128(43.4 \%)$ & $168,470(22.0 \%)$ & 0.002 \\
\hline In-hospital mortality & $41(12.3 \%)$ & $19,298(2.45 \%)$ & 0.02 \\
\hline
\end{tabular}


Table 3. Comparing basic HT demographics.

\begin{tabular}{|c|c|c|c|}
\hline & $\begin{array}{l}\text { Heart transplant } \\
\text { with myoclonus } \\
\text { N: } 147\end{array}$ & $\begin{array}{c}\text { Heart transplant } \\
\text { without myoclonus } \\
\mathrm{N}: 56,271\end{array}$ & $P$ value \\
\hline Age $($ mean \pm SD) & $64.8 \pm 10.3$ & $55.4 \pm 20.4$ & 0.01 \\
\hline Age $\geq 65$ yrs & $83(56.8 \%)$ & $23,644(42.0 \%)$ & 0.12 \\
\hline Female & $34(23.2 \%)$ & $16,130(28.3 \%)$ & 0.48 \\
\hline \multicolumn{4}{|l|}{ Medical Comorbidities } \\
\hline Diabetes Mellitus & $89(60.6 \%)$ & $23,625(41.2)$ & 0.04 \\
\hline Congestive Heart Failure & $24(16.0 \%)$ & $6552(11.6 \%)$ & 0.47 \\
\hline Hypertension & $94(63.7 \%)$ & $35,523(63.1 \%)$ & 0.94 \\
\hline Hyperlipidemia & $83(56.9 \%)$ & $23,394(41.6 \%)$ & 0.11 \\
\hline Atrial Fibrillation & $9(6.5 \%)$ & $4883(8.67 \%)$ & 0.63 \\
\hline Renal Failure & $94(64.0 \%)$ & $27,520(48.9 \%)$ & 0.08 \\
\hline Hypercoagulable state & 0 & 3905 (6.93\%) & - \\
\hline Chronic Lung Disease & $19(13.0 \%)$ & $8225(14.6 \%)$ & 0.78 \\
\hline \multicolumn{4}{|l|}{ In-hospital complications } \\
\hline Acute Kidney Injury & $98(66.8 \%)$ & $20,843(37.0 \%)$ & 0.01 \\
\hline Pneumonia & $19(13.2 \%)$ & $5776(10.3 \%)$ & 0.63 \\
\hline Urinary Tract Infection & $4.5(3.11 \%)$ & $4939(8.77 \%)$ & 0.09 \\
\hline Sepsis & $29(19.8 \%)$ & $4145(7.36 \%)$ & 0.15 \\
\hline \multicolumn{4}{|l|}{ Outcomes } \\
\hline Prolonged length of stay & $83(56.5 \%)$ & $14,647(26.0 \%)$ & 0.002 \\
\hline $\begin{array}{l}\text { Discharge disposition } \\
\text { of alive patients to } \\
\text { nursing home }\end{array}$ & $39(30.7 \%)$ & $6267(11.4 \%)$ & 0.05 \\
\hline In-hospital mortality & $19(13.5 \%)$ & $1167(2.07 \%)$ & 0.08 \\
\hline
\end{tabular}


Table 4. Comparing HT vs CABG demographics.

\begin{tabular}{|c|c|c|c|}
\hline & $\begin{array}{c}\text { Heart transplant } \\
\text { with myoclonus } \\
\mathrm{N}: 147\end{array}$ & $\begin{array}{l}\text { CABG with } \\
\text { myoclonus } \\
\mathrm{N}: 338\end{array}$ & $P$ value \\
\hline Age (mean \pm SD) & $64.8 \pm 10.3$ & $65.2 \pm 14.4$ & 0.90 \\
\hline Age $\geq 65$ yrs & $83(56.8 \%)$ & $190(56.2 \%)$ & 0.93 \\
\hline Female & $34(23.2 \%)$ & $77(23.0 \%)$ & 0.98 \\
\hline \multicolumn{4}{|l|}{ Medical Comorbidities } \\
\hline Diabetes Mellitus & $89(60.6)$ & $153(45.3)$ & 0.123 \\
\hline Congestive Heart Failure & $24(16.0)$ & 0 & - \\
\hline Hypertension & $94(63.7)$ & $264(78.0)$ & 0.215 \\
\hline Hyperlipidemia & $83(56.9)$ & $168(49.6)$ & 0.463 \\
\hline Atrial Fibrillation & $9(6.5)$ & $131(38.8)$ & $<0.0001$ \\
\hline Renal Failure & $94(64.0)$ & $96(28.4)$ & 0.0002 \\
\hline Hypercoagulable state & 0 & $103(30.6)$ & - \\
\hline Chronic Lung Disease & $19(13.0)$ & $84(0.24)$ & 0.086 \\
\hline \multicolumn{4}{|l|}{ In-hospital complications } \\
\hline Acute Kidney Injury & $98(66.8)$ & $132(39.1)$ & 0.011 \\
\hline Pneumonia & $19(13.2)$ & $40(11.8)$ & 0.819 \\
\hline Urinary Tract Infection & $4.5(3.11)$ & $28(8.41)$ & 0.231 \\
\hline Sepsis & $29(19.8)$ & $18(5.55)$ & 0.103 \\
\hline \multicolumn{4}{|l|}{ Outcomes } \\
\hline Prolonged length of stay & $83(56.5)$ & $275(81.2)$ & 0.008 \\
\hline $\begin{array}{l}\text { Discharge disposition } \\
\text { of alive patients to } \\
\text { nursing home }\end{array}$ & $39(30.7)$ & $128(43.4)$ & 0.192 \\
\hline In-hospital mortality & $19(13.5)$ & $41(12.3)$ & 0.87 \\
\hline
\end{tabular}


Table 5. Comparing mortality with and without myoclonus.

\begin{tabular}{ccc}
\hline & Heart Transplant & CABG \\
\hline Mortality without Myoclonus & $2.07 \%$ & $2.45 \%$ \\
Mortality with Myoclonus & $13.6 \%$ & $12.3 \%$ \\
P value & 0.08 & 0.02 \\
\hline
\end{tabular}

\section{Discussion}

In this national representative retrospective study, we found higher rates of myoclonus in patients undergoing HT compared to those undergoing CABG surgery. The difference remained statistically significant after adjusting for potential confounders. Our findings suggest that CNIs may be a contributing factor to myoclonus.

Patients with HT were the preferred organ transplant group selected to study the effect of CNIs because of the high volumes and a similar representative control group (patients undergoing $\mathrm{CABG}$ ) with comparable surgical and anesthetic conditions. Both cases are done with cardiopulmonary bypass and the anesthetic management is very similar with the exception that CNIs are not administered during CABG. Kidney and liver transplant occur at a higher frequency than HT however finding a comparable control group for those organ transplants would be challenging due to the small number of cases that are done for reasons other than malignancy, i.e. For kidney and liver transplant, a comparable surgery would be hepatectomy or nephrectomy, however, few hepatectomies and nephrectomies are done for non-malignant causes which would therefore limit finding a sizable control group. Given the similar management during both cardiac surgeries, our findings suggest an association between myoclonus and CNIs.

Patients in the HT + myoclonus group had higher complication rates of acute kidney injury compared to those without myoclonus. The nephrotoxic effects of CNIs are well known [15]. Interestingly, patients in the CABG + myoclonus group also had higher complication rates of acute kidney injury despite not receiving CNIs. The authors postulate the hypothesis that there may be an association between renal injury and blood brain barrier dysfunction when other mechanisms lead to acute kidney injury in patients with CABG.

Neurotoxicity has previously been associated to CNIs [4] [6] [8] [9] [16] [17]. In a study published by Adams et al., 13 of 52 orthotopic liver transplants had "fits" (10 grand mal seizure, 2 myoclonus, and 1 focal seizure) [18]. In another study, up to $40 \%$ of patients had upper extremity tremors while receiving cyclosporin or tacrolimus after lung or liver transplant [11] [19]. The toxic effects of CNIs are in part due to inhibition of calcineurin by binding to proteins in the cells called immunophilins. Calcineurins are a calcium/calmodulin-dependent protein phosphatase involved in intracellular signaling involved in many physiological processes. High amounts of calcineurins are found in both lymphocytes and within neuronal cells. It is particularly concentrated within the cell body, 
post synaptic terminals, and axons of neurons. Immunophilins like FKBP12 and cyclophilin are proteins responsible for regulating cellular function including protein folding within the central and peripheral nervous system. It is postulated that the relative amounts and distribution of immunophilins within nerve tissue of each individual may account for the variation and severity of the symptoms to CNIs [20]. Calcineurins themselves exist in several isoforms which all have different degrees of susceptibility to inhibition. This may also account for the differences in rates of neurotoxicity that are observed in these patients [21].

Calcitonin inhibitors are lipophilic agents but contain many aliphatic groups. Under normal physiologic conditions the blood brain barrier limits the access of CNIs to neurons [22]. However, several disease processes (including hypertension, aging, autoimmune disease, and chronic systemic inflammation) have been linked to compromised functionality of the brain blood brain barrier and increased permeability [23] [24] [25] [26] [27]. Interestingly, bovine blood brain barrier models have demonstrated that proinflammatory cytokines and nitric oxide produced by glial cells may contribute to this disruption [28] [29]. Low cholesterol levels have also been shown to elevate Low Density Lipoprotein (LDL) expression on cells. Arachnoid and astrocyte cells primarily express LDL receptors and are vital for maintenance of the blood brain barrier. There is binding of CNIs to LDL receptors to gain entry into these cells exposing them to their toxicity [30]. Patients who have underlying inflammatory states, hypertension, or lower cholesterol levels could therefore be at particular risk for increased blood brain barrier permeability and consequently to CNIs and their toxicity.

In this particular study, although patients in the CABG + myoclonus group had a higher mortality than those without myoclonus this did not hold true for the HT + myoclonus group, Table 5 . However, there was a trend toward a statistically significant difference and the authors attributed the low number of HT cases in this national database that underpowered the study to achieve a statistically significant difference. Had the period of study been longer the difference would have been achieved.

Given our findings, the authors suspect that myoclonus may be a clinical indicator of the overall health of these patients, the endothelium health and the health of the blood brain barrier. If chronic disease states can lead to a disrupted and more permeable blood brain barrier, it could likely expose the neural tissue to different caustic agents. Likewise, the compromised function of other organs and systems may also make patients susceptible to neurotoxicity. If the hypothesis of myoclonus as an indicator of poor blood brain barrier function holds true, it stands to reason that even in the absence of CNIs, those patients with chronic conditions or factors that increase the blood brain barrier permeability would still be susceptible to myoclonus and would still have higher rates of mortality through other neurotoxic agents and/or physiologic disturbances. Myoclonus was present in some of these patients in the CABG group despite not being on CNIs. 
There are limitations to this study that must be acknowledged. The study was retrospective which presents challenges to mitigating bias and confounding variables. The model used for comparison was surgical patients under general anesthesia. The environment itself introduces variables that cannot readily be controlled or excluded. For example, anesthetic agents like etomidate can also cause myoclonus, however its use is limited to the general anesthesia period. Excluding the use of CNIs for HT, the impact, the anesthetics by themselves would have on the incidence of myoclonus in one group versus the other should be negligible. Patients under general anesthesia have blunted autoregulation of the central nervous system which leads to a more linear relationship between Mean Arterial Pressure (MAP) and Cerebral Blood Flow (CBF). There is the possibility while under general anesthesia increases in MAP including during cardiopulmonary bypass would allow a greater delivery of agents like CNIs across the blood brain barrier due to the increased cerebral blood flow. This enhanced delivery could exaggerate the differences in myoclonus rates between the HT group vs CABG group due to the presence of CNIs. As mentioned previously, nitric oxide appears to play a role in the permeability of the blood brain barrier. There are instances where patients with a history of right heart dysfunction or who are undergoing heart transplant would be placed on inhaled nitric oxide perioperatively. This theoretically could increase the permeability of the blood brain barrier regardless of the general state of health of its endothelium. The authors were not able to exclude the impact inhaled nitric oxide might have had within both groups. However, the use of nitric oxide is not commonly used and should not affect the overall results.

Notwithstanding the limitations of the study, our data indicate significant higher rates of myoclonus within the HT group. Our findings remained after controlling for confounders suggesting that the CNIs and their neurotoxicity may be contributing factors to the higher rates of myoclonus observed in the HT group. A higher mortality rate was observed in patients in the CABG + myoclonus group and a trend in the HT + myoclonus compared to those without myoclonus. The higher mortality observed may implicate the presence of multiple chronic co-morbidities, including dysfunction of the blood brain barrier. More prospective studies are needed to reproduce our findings and to study the significance of myoclonus as a surrogate marker of blood brain barrier function.

\section{Conflicts of Interest}

The authors declare no conflicts of interest regarding the publication of this paper.

\section{References}

[1] Eberhardt, O. and Topka, H. (2017) Myoclonic Disorders. Brain Sciences, 7, Article No. 103. https://doi.org/10.3390/brainsci7080103

[2] Sarva, H. and Panichpisal, K. (2012) Gentamicin-Induced Myoclonus: A Case Report and Literature Review of Antibiotics-Induced Myoclonus. Neurologist, 18 
385-388. https://doi.org/10.1097/NRL.0b013e3182704d78

[3] Janssen, S., Bloem, B.R. and van de Warrenburg, B.P. (2017) The Clinical Heterogeneity of Drug-Induced Myoclonus: An Illustrated Review. Journal of Neurology, 264, 1559-1566. https://doi.org/10.1007/s00415-016-8357-Z

[4] Ghaus, N., Bohlega, S. and Rezeig, M. (2001) Neurological Complications in Liver Transplantation. Journal of Neurology, 248, 1042-1048. https://doi.org/10.1007/s004150170023

[5] de Groen, P.C., Aksamit, A.J., Rakela, J., Forbes, G.S. and Krom, R.A.F. (1987) Central Nervous System Toxicity after Liver Transplantation. New England Journal of Medicine, 317, 861-866. https://doi.org/10.1056/NEJM198710013171404

[6] Eidelman, B.H., Abu-Elmagd, K., Wilson, J., Fung, J.J., Alessiani, M., Jain, A., Takaya, S., Todo, S.N., Tzakis, A., Van Thiel, D., et al. (1991) Neurologic Complications of FK 506. Transplantation Proceedings, 23, 3175-3178.

[7] Mayer, A.D., Dmitrewski, J., Squifflet, J.P., Besse, T., Grabensee, B., Klein, B., Eigler, F.W., Heemann, U., Pichlmayr, R., Behrend, M., Vanrenterghem, Y., Donck, J., van Hooff, J., Christiaans, M., Morales, J.M., Andres, A., Johnson, R.W., Short, C., Buchholz, B., Rehmert, N., Land, W., Schleibner, S., Forsythe, J.L., Talbot, D., Pohanka, E., et al. (1997) Multicenter Randomized Trial Comparing Tacrolimus (FK506) and Cyclosporine in the Prevention of Renal Allograft Rejection: A Report of the European Tacrolimus Multicenter Renal Study Group. Transplantation, 64, 436-443. https://doi.org/10.1097/00007890-199708150-00012

[8] Walker, R.W. and Brochstein, J.A. (1988) Neurologic Complications of Immunosuppressive Agents. Neurologic Clinics, 6, 261-278.

https://doi.org/10.1016/S0733-8619(18)30869-7

[9] Bechstein, W.O. (2000) Neurotoxicity of Calcineurin Inhibitors: Impact and Clinical Management. Transplant International, 13, 313-326. https://doi.org/10.1111/j.1432-2277.2000.tb01004.x

[10] Qureshi, A.I., Chaudhry, S.A., Hassan, A.E., Zacharatos, H., Rodriguez, G.J., Suri, M.F., Lakshminarayan, K. and Ezzeddine, M.A. (2011) Thrombolytic Treatment of Patients with Acute Ischemic Stroke Related to Underlying Arterial Dissection in the United States. Archives of Neurology, 68, 1536-1542.

https://doi.org/10.1001/archneurol.2011.213

[11] Mandawat, A., Kaminski, H.J., Cutter, G., Katirji, B. and Alshekhlee, A. (2010) Comparative Analysis of Therapeutic Options Used for Myasthenia Gravis. Annals of Neurology, 68, 797-805. https://doi.org/10.1002/ana.22139

[12] Mulloy, D.P., Bhamidipati, C.M., Stone, M.L., Ailawadi, G., Kron, I.L. and Kern, J.A. (2013) Orthotopic Heart Transplant versus Left Ventricular Assist Device: A National Comparison of Cost and Survival. Journal of Thoracic and Cardiovascular Surgery, 145, 566-574. https://doi.org/10.1016/j.jtcvs.2012.10.034

[13] LaPar, D.J., Stukenborg, G.J., Guyer, R.A., Stone, M.L., Bhamidipati, C.M., Lau, C.L., Kron, I.L. and Ailawadi, G. (2012) Primary Payer Status Is Associated with Mortality and Resource Utilization for Coronary Artery Bypass Grafting. Circulation, 126, S132-139.

[14] Cruz-Flores, S., Rodriguez, G.J., Chaudhry, M.R.A., Qureshi, I.A., Qureshi, M.A., Piriyawat, P., Vellipuram, A.R., Khatri, R., Kassar, D. and Maud, A. (2019) Racial/Ethnic Disparities in Hospital Utilization in Intracerebral Hemorrhage. International Journal of Stroke, 14, 686-695. https://doi.org/10.1177\%2F1747493019835335

[15] Rush, D. (2013) The Impact of Calcineurin Inhibitors on Graft Survival. Transplan- 
tation Reviews, 27, 93-95. https://doi.org/10.1016/j.trre.2013.04.003

[16] Anghel, D., Tanasescu, R., Campeanu, A., Lupescu, I., Podda, G. and Bajenaru, O. (2013) Neurotoxicity of Immunosuppressive Therapies in Organ Transplantation. Maedica (Bucur), 8, 170-175.

[17] Thompson, C.B., June, C.H., Sullivan, K.M. and Thomas, E.D. (1984) Association between Cyclosporin Neurotoxicity and Hypomagnesaemia. Lancet, 2, 1116-1120. https://doi.org/10.1016/S0140-6736(84)91556-3

[18] Adams, D.H., Gunson, B., Honigsberger, L., Buckels, J., Ponsford, S., Boon, A., Williams, A., Elias, E. and McMaster, P. (1987) Neurological Complications Following Liver Transplantation. Lancet, 329, 949-951. https://doi.org/10.1016/S0140-6736(87)90294-7

[19] Tan, T.C. and Robinson, P.J. (2006) Mechanisms of Calcineurin Inhibitor-Induced Neurotoxicity. Transplantation Reviews, 20, 49-60. https://doi.org/10.1016/j.trre.2006.02.005

[20] Kung, L. and Halloran, P.F. (2000) Immunophilins May Limit Calcineurin Inhibition by Cyclosporine and Tacrolimus at High Drug Concentrations. Transplantation, 70, 327-335. https://doi.org/10.1097/00007890-200007270-00017

[21] Halloran, P.F., Kung, L. and Noujaim, J. (1998) Calcineurin and the Biological Effect of Cyclosporine and Tacrolimus. Transplantation Proceedings, 30, 2167-2170. https://doi.org/10.1016/S0041-1345(98)00577-6

[22] Wijdicks, E.F. (2001) Neurotoxicity of Immunosuppressive Drugs. Liver Transplantation, 7, 937-942. https://doi.org/10.1053/jlts.2001.27475

[23] Biancardi, V.C., Son, S.J., Ahmadi, S., Filosa, J.A. and Stern, J.E. (2014) Circulating Angiotensin II Gains Access to the Hypothalamus and Brain Stem during Hypertension via Breakdown of the Blood-Brain Barrier. Hypertension, 63, 572-579. https://doi.org/10.1161/HYPERTENSIONAHA.113.01743

[24] Lossinsky, A.S. and Shivers, R.R. (2004) Structural Pathways for Macromolecular and Cellular Transport across the Blood-Brain Barrier during Inflammatory Conditions. Review. Histology and Histopathology, 19, 535-564. https://doi.org/10.14670/hh-19.535

[25] Setiadi, A., Korim, W.S., Elsaafien, K. and Yao, S.T. (2018) The Role of the BloodBrain Barrier in Hypertension. Experimental Physiology, 103, 337-342. https://doi.org/10.1113/EP086434

[26] Stolp, H.B., Dziegielewska, K.M., Ek, C.J., Potter, A.M. and Saunders, N.R. (2005) Long-Term Changes in Blood-Brain Barrier Permeability and White Matter Following Prolonged Systemic Inflammation in Early Development in the Rat. European Journal of Neuroscience, 22, 2805-2816.

https://doi.org/10.1111/j.1460-9568.2005.04483.x

[27] Zheng, W. (2001) Neurotoxicology of the Brain Barrier System: New Implications. Journal of Toxicology: Clinical Toxicology, 39, 711-719. https://doi.org/10.1081/CLT-100108512

[28] Boveri, M., Kinsner, A., Berezowski, V., Lenfant, A.M., Draing, C., Cecchelli, R., Dehouck, M.P., Hartung, T., Prieto, P. and Bal-Price, A. (2006) Highly Purified Lipoteichoic Acid from Gram-Positive Bacteria Induces in Vitro Blood-brain Barrier Disruption through Glia Activation: Role of Pro-Inflammatory Cytokines and Nitric Oxide. Neuroscience, 137, 1193-1209. https://doi.org/10.1016/j.neuroscience.2005.10.011

[29] Dohgu, S., Yamauchi, A., Nakagawa, S., Takata, F., Kai, M., Egawa, T., Naito, M., Tsuruo, T., Sawada, Y., Niwa, M. and Kataoka, Y. (2004) Nitric Oxide Mediates 
Cyclosporine-Induced Impairment of the Blood-Brain Barrier in Cocultures of Mouse Brain Endothelial Cells and Rat Astrocytes. European Journal of Pharmacology, 505, 51-59. https://doi.org/10.1016/j.ejphar.2004.10.027

[30] de Groen, P.C. (1988) Cyclosporine, Low-Density Lipoprotein, and Cholesterol. Mayo Clinic Proceedings, 63, 1012-1021. https://doi.org/10.1016/S0025-6196(12)64916-7 


\section{Glossary of Terms}

Afib-Atrial Fibrillation

ANOVA-Analysis of Variance

CABG-Coronary Bypass Graft

CBF-Cerebral Blood Flow

CNI-Calcineurin Inhibitors

DM-Diabetes Mellitus

HT-Heart Transplant

HTN-Hypertension

ICD-9-CM-International Classification of Disease, $9^{\text {th }}$ Revision, Clinical Modification

LDL_Low Density Lipoprotein

LOS-Length of Stay

MAP-Mean Arterial Pressure

NIS-Nationwide Inpatient Sample

PLOS-Prolonged Length of Stay

Schematic Diagram of NIS Data Sampling Selection

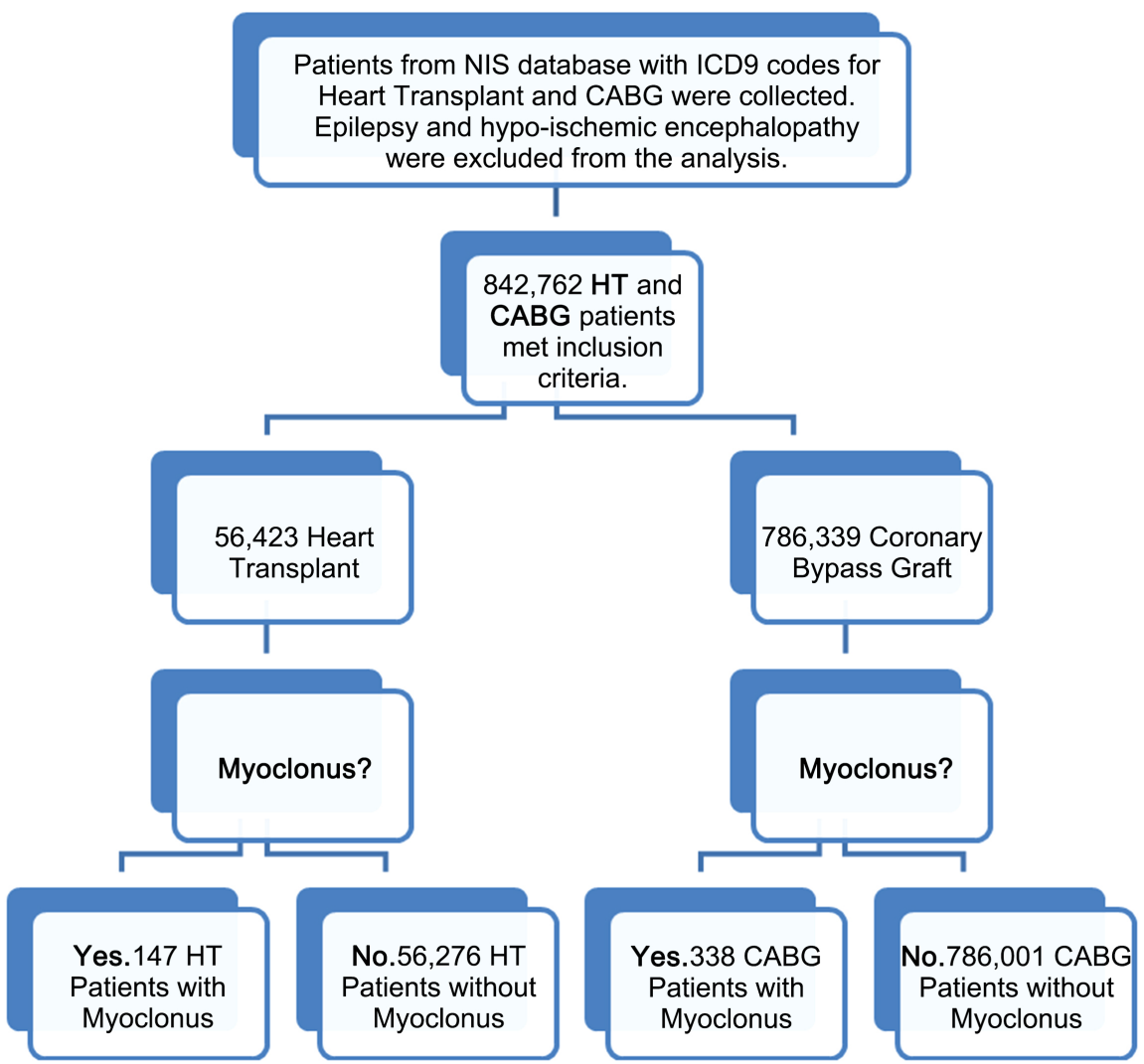

